\title{
Reiter's Syndrome Associated with the Acquired Immunodeficiency Syndrome: A Case Report
}

\author{
Malta J.B.N.S., Milanelo D., \\ Carvalheiro F.A.R. and Silva M.V.
}

\author{
Catholic University of São Paulo; Emílio Ribas \\ Institute; Health Office of São Paulo, SP; College of \\ Medicine of Sorocaba, SP, Brazil
}

\begin{abstract}
The association of Reiter's Syndrome (RS) with the Acquired Immunodeficiency Syndrome (AIDS) is seldom mentioned in the medical literature. This report illustrates this relationship in a 46 years old male patient suffering from $\operatorname{AIDS}\left(\mathrm{CD}_{4}^{+}=240 \mathrm{cells} / \mathrm{mm}^{3}, \mathrm{CD}_{8}^{+}=1,301 \mathrm{cells} / \mathrm{mm}^{3}\right.$ and viral load $=330,000$ copies $/ \mathrm{ml}$ ), pulmonary tuberculosis (positive catarrhal bacilluscopy), and RS. The diagnosis of RS was based on the combination of dermatological and articular alterations. The patient's cutaneous lesions were characterized by exfoliation and the formation of crusts located on the face, scalp, genitals, hands, and feet; onychodystrophy with opacity; yellowish coloring; and hyperkeratosis of the nails. Articular lesions led to progressive deformity of phalangeal joints of the hands, and intensive arthralgia, mainly of the larger joints (shoulders, elbows, hips and knees). AIDS treatment was administered with anti-retroviral drugs (zidovudine and didanosine); for tuberculosis (isoniazid, rifampicine, and pyrazinamide); and (prednisone and inometacine) for the RS. The patient recovered with the improvement of articular symptoms; however, on the eighth day of treatment, the patient showed significant hemoptysis and hypovolemic shock, and died. The association of RS and HIV infection is reviewed.

Key Words: Reiter's syndrome, acquired immunodeficiency syndrome, AIDS.
\end{abstract}

Reiter's Syndrome (RS) fits into the spectrum of specific organic pathology of the reactive arthritis group [1], with the addition of extra articular manifestations. The syndrome is defined by the classical triad of arthritis, urethritis, and conjunctivitis [2]. However, the complete triad is observed in only $33 \%$ of patients. Thus, the American College of Rheumatology (ACR) established alternate criteria for the diagnosis of this condition that were the presence of arthritis in the extremities of longer than 1 month duration plus associated urethritis and/or cervicitis. Using these criteria, the diagnosis is made with $84 \%$ sensitivity and a $98.2 \%$ specificity [3].

Received on 19 March 2001; revised 4 October 2001.

Address for correspondence: Dr. João Batista Malta - Rua Prof. Artur Ramos, 183; $3^{\circ}$ andar, cj. 32, São Paulo, SP - Zip code: 01454-011-Email:jbmalta@hotmail.com

The Brazilian Journal of Infectious Diseases 2002;6(1):40-44 (C) 2002 by The Brazilian Journal of Infectious Diseases and Contexto Publishing. All rights reserved.

$1413-8670$
Because rheumatoid factor is not detectable in these patients, the diagnosis of RS is based on clinical findings and in the evolution of the disease $[3,4]$.

In this report, we describe a case of $\mathrm{RS}$ with articular and extra articular manifestations associated with AIDS, that had a chronic, recurrent course of the illness.

\section{Case Report}

This is a white male patient, 46 years old, former illicit injected drug user, former convict, with a history of sexual promiscuity without the use of prophylactics. The HIV had been confirmed by laboratory diagnosis 7 years before. The patient was hospitalized with a diagnosis of AIDS, pulmonary tuberculosis, and dermatitis of unknown etiology.

Upon admittance, the patient complained of coughing with bloody expectoration and severe joint pain, mainly in the larger joints (shoulders, elbows, hips and knees), for five days. On physical examination, it 
was found that the patient was in generally poor health, pale, dehydrated, with whitish lesions on the oral mucosa, suggesting candidiasis. Crusty lesions always exfoliating and painless - were found mainly on the face, scalp, genitals, hands, and feet (Figures 1 to 3$)$.

The patient reported that dermatological manifestations, characterized by crusty and exfoliating lesions on the lower limbs, followed by knee and ankle arthralgia had begun 3 years earlier followed by a period of spontaneous remission. A year later, the symptoms recurred more intensely and extensively when the cutaneous lesions spread over the patient's trunk, face and scalp, followed by arthralgia of shoulders and wrists. Again, the patient showed signs of recovery, even though he could not specify which medication had been used.

Approximately 7 months prior to hospitalization, the patient started to show progressive articular deformities of the hands, compromising mainly the inter-phalangeal articulations. Two months before admissions, these symptoms intensified with general loss of body weight (approximately $12 \mathrm{~kg}$ during this period) diarrhea, and a complaint of strong arthralgia in large and small joints.

Physical examination demonstrated exfoliating lesions of the skin, with grayish adhesive crusts on the forehead and scalp (Figure 1). Erythrodermic and exfoliating lesions were present in the genital areas (Figure 2); there were crusty and erythrodermic lesions of intense exfoliation and hyperkeratosis on the hands and bilateral exfoliation with pustules and hyperkeratosis on the feet. The hands presented articular deformities with amyotrophia. The nails showed onychodystrophy with opacity, yellowish coloring and hyperkeratosis (Figure 3 ). The patient denied dysuria and other urinary symptoms, and his ophthalmological exam was normal.

Laboratory tests revealed anemia (Hb: $6.5 \mathrm{~g} / \mathrm{dl})$, leucocytosis $\left(13,700\right.$ cells $\left./ \mathrm{mm}^{3}\right)$, hyponatraemia ( $\mathrm{Na}$ : $133 \mathrm{mEg} / \mathrm{l})$, the presence of alcohol-acid resistant bacilli ("BAAR") in sputum, and positive serum antobody tests for anti-hepatitis virus $\mathrm{C}$ (Elisa) and anti-HIV (ELISA and Western Blot). The VDRL was non-reactive. The count of $\mathrm{CD}_{4}^{+}$cells was 240 cells/ $\mathrm{mm}^{3}$ and of $\mathrm{CD}_{8}^{+}\left(1,301\right.$ cells $\left./ \mathrm{mm}^{3}\right)\left(\mathrm{CD}_{4}^{+} / \mathrm{CD}_{8}^{+}=\right.$ 0.18). Viral load ("NASBA") detected 330,000 copies/ml. Thorax X-ray showed a cavitation in the left pulmonary apex; intradermal reaction with PPD was positive with enduration of $14 \mathrm{~mm}$.

The patient started treatment with antiretroviral drugs zidovudive $600 \mathrm{mg} /$ day and didanosine $400 \mathrm{mg} /$ day, isoniazid $400 \mathrm{mg} / \mathrm{day}$, pirazinamide $2 \mathrm{~g} /$ day and rifampicine $600 \mathrm{mg} /$ day for tuberculosis, and prednisone $30 \mathrm{mg} /$ day together with indometacin $50 \mathrm{mg} /$ day for treating RS, a mild opiate analgesic, antiemetic, and cimetidine.

The patient recovered significantly from articular pain, but still had cough and haemoptysis. On the eighth day after hospital admittance, the patient had severe haemoptysis, and hypovolemic shock, and died.

\section{Discussion}

In this case involving AIDS and RS, clinical alterations were observed, characterized by cutaneous manifestations (exfoliating and crusty lesions) and articular symptoms (deformity of the hands and arthralgia of small and large articulations). Arthralgia of the lower limbs was present since the first sign of RS three years before; during the second and third stages, the upper limbs were also affected.

Clinical examination of the patient was important for the confirmation of a diagnosis of RS. The criteria applied in the diagnosis were the presence of articular and extra articular symptoms, such as blennorrhagic dermal keratosis, an episode of diarrhea two months earlier, and HIV infection. The patient also had anemia and leukocytosis.

Cutaneous lesions found on this patient, with the presence of crusts and exfoliation, are the same as those encountered in blennorrhagic keratodermal conditions. These lesions are the most common cutaneous signs in $\mathrm{RS}$, and are characterized by papulosquamous, painless lesions found on plantar and/or palmar regions [2]. Besides these, intense onychodystrophy has been noted with opacity, yellowish coloring and hyperkeratonization 
Figure 1. Exfoliating lesions with grayish adhesive crusts on the forehead and scalp

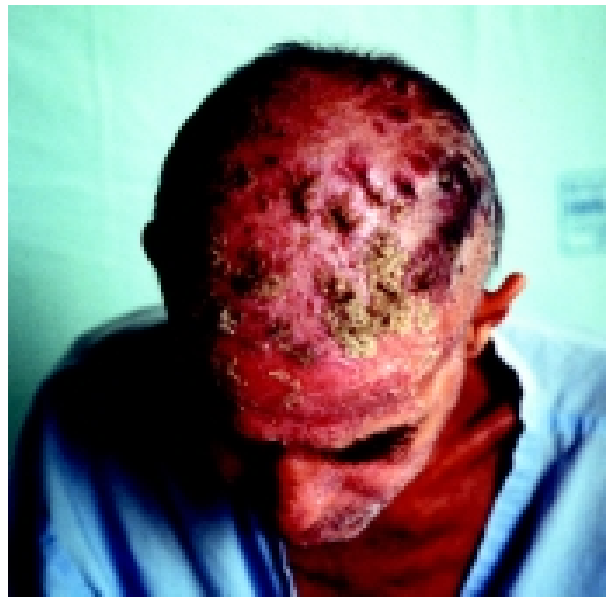

Figure 2. Erythrodermic and exfoliating lesions in the genital area

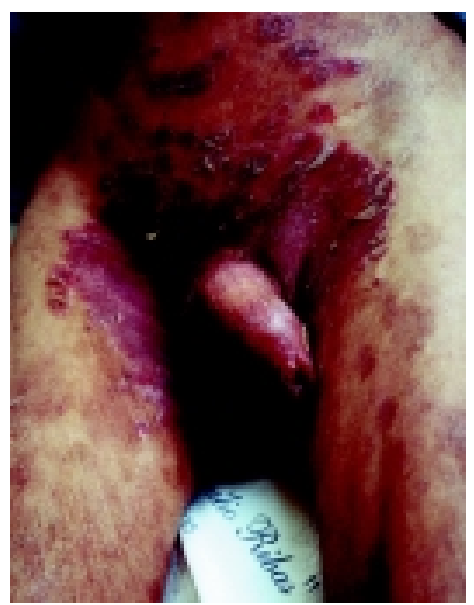

Figure 3. Hands showing onychodystrophy of nails with opacity and hyperkeratosis; feet showing bilteral exfoliation with pustules and hyperkeratosis

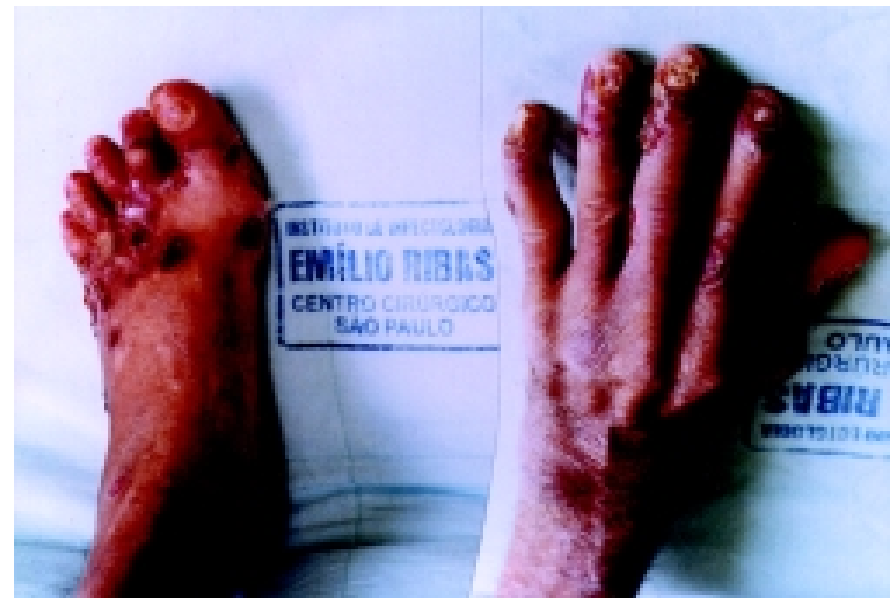


of the fingernails and toenails. These alterations are common among patients who develop chronic arthropathy [3].

The early symptoms of RS generally appear within 4 weeks after infection. Clinical manifestations such as dysuria, prostatitis in men, and cervicitis in women may be a result of infections in the genitourinary tract. The following signs may also be noted: fever, fatigue, weight loss, and ocular symptoms (conjunctivitis, uveitis and keratitis). Arthritis is usually the last symptom to evolve, which happens between 1 and 4 weeks. The involvement of the joints of the lower limbs is more common, and it may progress to the upper limbs and vertebral column. Digital damage is generally followed by dactylitis [3,9].

Other manifestations may also occur such as inflammation at the bone insertion of tendons and ligaments (tendenitis), muco-cutaneous and cardiac manifestations. RS usually effects the young, but there is also increased frequency among individuals over 65 . Males predominate at a 5:1 ratio $[1,2]$. The association between RS and the Acquired Immunodeficiency Syndrome (AIDS) was first described in 1987. RS with AIDS is a more serious condition than in nonAIDS patients, showing rapid progression and being quite refractory to treatment [5]. RS is frequently associated with progressive infection by pathogenic micro-organisms such as: shingella, salmonella, yersinia, campylobacter and chlamydia [6,7]. However, Cush and Lipsky [3] observed that only one third of RS or AIDS patients presented prior genital or enteric infection.

According to Medina et al. [6], rheumatic manifestations occurred in $8 \%$ of HIV positive patients, compared in their series to none in HIV negative patients. Monoz et al. [7] observed the occurrence of RS in only $0,4 \%$ of 556 HIV positive patients, with rheumatic manifestations. This observation coincides with Keat and Rowe's report [8], where prevalence varied between $0.3 \%$ and $10 \%$.

Cush and Lipsky [2], and Winchester et al. [4] showed that the classical triad of RS was not observed in $66 \%$ of all patients studied. The diagnosis was established through clinical criteria including acute oligoarthritis of lower limbs, followed by extra articular manifestations such as diarrhea, urethritis, cervicitis, ocular inflammation, lumbago, enteritis, blennorrhagic dermal keratosis, and other mucocutaneous lesions.

Gomes et al. [9] demonstrated that prior episodes of arthralgia in large joints with skin manifestations associated with current clinical manifestations led to a diagnosis of RS in $28 \%$ of the 25 patients they studied. In $87 \%$ of those patients, urethritis and ocular symptoms, predominantly conjunctivitis, were present in $76 \%$ of the cases.

Buskila et al. [10] encountered 4\%, and Berman et al. [11] 10\%, of study patients carrying RS, and, among those none presented the classical triad. According to these results, it is clear that the association between RS and AIDS is rare, with few cases described in the literature.

Pavlica et al. [8], and Keat et al. [6] report that $60 \%$ to $80 \%$ of the patients with RS are HLA-B27 positive, thus showing a strong relation between HLAB27 and RS, suggesting that this test should be conducted for a diagnosis. According to Winchester et al. [12], the probability that HLA-B27 positive individuals develop reactive arthritis or RS after exposure to arthrogenic microorganisms has been estimated in $20 \%$. However, due to the small number of HLA-B27 positive individuals contract RS, the predictive value of this test is low and, therefore, not a useful assessment tool [3]. The high costs combined with the low predictive value, and the low specificity of the test discourage its use. The abnormal lab results frequently found in RS include leukocytosis, thrombocytosis, and anemia, and an elevation of hepatic enzyme values may still occur in the uncontrolled illness [1].

In the medical therapy of RS, non-hormonal antiinflammatory drugs such as indomethacin, naproxene, and diclofenaco are administered. The patient's commitment to the treatment is very important for a successful outcome.

Among AIDS and RS patients, the later tend to have a more severe clinical course, with greater resistance to conventional therapy $[5,13]$. The RS treatment with arthropathy is more difficult because a 
considerable number of patients do not respond well to the usual non-hormonal anti-inflammatory drugs, and, sometimes, not even to steroids. [12].

Prognosis and evaluation of RS are variable and unpredictable. The majority of patients show an initial stage of 2 to 3 months, sometimes persisting for up to 1 year. Recurrent crises and extended intervals of remission are common [2]. Serious sequelae occur in less than $15 \%$ of patients, and generally result in damage to the lower limbs and blindness [3].

The association between RS and AIDS has been explained by the fact that the acquired immunodeficiency allows bacterial, viral and parasitic infections caused by microorganisms with arthrogenic potential - enabling the occurrence of RS [6]. Another suggested possibility is that the immunological disarray caused by AIDS, or resulting from an increase in the population of lymphocytes $\mathrm{CD}_{8}^{+}$may lead to the appearance of RS [12-14]. A third possibility is that immune activation caused by RS may activate latent HIV infection. The authors of this report raise the possibility that HIV infection itself could be a trigger for the appearance of RS.

\section{References}

1. Mello e Silva A. C., Boulos M. Reiter's syndrome and immunodeficiency virus infection. Rev. Hosp. Clin. Fac. Med. São Paulo 1998;53(4):202-4.

2. Cush J., Lipsky P. Spondyloarthropathies. In: Cecil Medicina Interna. Philadelphia 20ed, 1996, p. 1624-6.

3. Cush J., Lipsky P. Reiter's syndrome and reactive arthritis. In: Arthritis and Allied Conditions - A Textbook of Rheumatology. Pennsylvania, 12ed, 1993, p. 1061-72.

4. Pavlica L., Mitrovic D., Mladenovic V., et al. Reiter's syndrome - analysis of 187 patients. Vojnosanit Pregl 1997;54(5):437-46.

5. Winchester R., Bernstein D.H., Fischer H.D., et al. The co-occurrence of Reiter's Syndrome and Acquired Immunodeficiency. Ann Intern Med 1987;106:19-26.

6. Medina-Rodriguez F., Guzman C., Jara C.J., et al. Rheumatic manifestations in human immudeficiency virus positive and negative individuals: a study of 2 populations with similar risk factors. J Rheumatol 1993;20(11):1880-4.
7. Munoz F.S., Cardenal A., Balsa A., et al. Rheumatic Manifestations in 556 patients with human immunodeficincy virus infection. Semin Arthritis 1991;21(1):30-9.

8. Keat A., Rowe I. Reiter's syndrome and associated arthritides. Rheum Dis Clin North Am 1991;17(1):25-42.

9. Gomes R.N., Sanchez B.J., Grana G.J., et al. Reiter's syndrome - a study of 25 cases. An Med Interna 1990;7(9):446-50.

10. Buskila D., Gladman D.D., Langevitz P., et al. Rheumatologic manifestations of infection with the Human Immunodeficiency Virus (HIV). Clin Exp. Rheumatol 1990;8:567-73.

11. Berman A., Espinoza L.R., Diaz J.D., et al. Rheumatic manifestations of human immunodeficiency virus infection. Am J Med 1988;85:59-64.

12. Winchester R., Brancato L., Itescu S., et al. Implications from the occurrence of Reiter's syndrome and related disorders in association with advanced HIV infection. Scand J Rheumatol Suppl 1988;74:89-93.

13. Fuente C., VelezA., Martin N., et al. Reiter's syndrome and human immunodeficiency virus infection: case report and review of the literature. Cutis 1991;47(3):181-5.

14. Clark M.R., Solinger A.M., Hochberg M.C. Human immunodeficiency virus infection is not associated with Reiter's syndrome. Rheum Dis Clin North Am 1992; 18(1):267-76. 